\title{
Study on Pharmacokinetics, Tissue Distribution, and Excretion of Phloretin and Its Prodrug 2', 4',6',4-Tetra-O-acetylphloretin in Rats Using LC-MS/MS
}

\author{
Libin Wang ${ }^{1 \dagger}, \mathrm{Xi} \mathrm{Li}^{2 \dagger}$, Le Mi ${ }^{1}$, Xin Shen ${ }^{1}$, Tian Feng ${ }^{1}$, Xueying Liu ${ }^{* *}$ and Qingwei Wang ${ }^{2 *}$ \\ ${ }^{1}$ Department of Medicinal Chemistry, School of Pharmacy, Medical University of the Air Force, Xi'an, China \\ ${ }^{2}$ Department of Pharmacy, Tangdu Hospital, Medical University of the Air Force, Xi'an 710038, China
}

Received: 31 July 2017; accepted: 12 September 2017

\begin{abstract}
$2^{\prime}, 4^{\prime}, 6^{\prime}, 4$-Tetra-O-acetylphloretin (TAPHL) is a prodrug of phloretin (PHL) in which the $\mathrm{OH}$ groups are protected by acetylation. A validated liquid chromatography-tandem mass spectrometry (LC-MS/MS) method for the determination of PHL in rat biological matrices was developed and applied to investigate and compare the pharmacokinetics, tissue distribution, and excretion of PHL and TAPHL in rats following a single oral administration. The method was validated for accuracy, precision, linearity, range, selectivity, lower limit of quantification (LLOQ), recovery, and matrix effect. All validation parameters met the acceptance criteria according to regulatory guidelines. The mean pharmacokinetic parameters of $t_{\max }, C_{\max }, \mathrm{AUC}_{(0-t)}, \mathrm{CL} / \mathrm{F}$, and $t_{1 / 2}$ were observed after oral administration in rats. The data showed that PHL was absorbed and eliminated rapidly from plasma after oral administration. The pharmacokinetic properties are improved, such as the $t_{\max }$ has been prolonged and the area under the curve (AUC) has been enhanced after oral administration of TAPHL to rats. Tissue distribution results indicated that PHL could be rapidly and widely distributed into tissues but could not effectively cross the blood-brain barrier in rats. After oral administration of TAPHL to rats, its tissue distribution to rats was similar as that after oral administration of equimolar PHL. In addition, higher recoveries of PHL following administration of TAPHL indicated that TAPHL might reduce the excretion of PHL from the body by reducing the first pass effect.
\end{abstract}

Keywords: Phloretin, 2',4',6',4-tetra-O-acetylphloretin, pharmacokinetics, tissue distribution, excretion

\section{Introduction}

Flavonoids are important natural organic compounds that are widely distributed in the plants. In the human diet, they are most concentrated in fruits, vegetables, wines, teas, and cocoa [1]. They are a class of polyphenol compound in plants, and many of them can decrease risk of major chronic diseases, including protecting cardiovascular [2, 3], digestive and respiratory systems $[4,5]$, anti-inflammatory [6-11], anticarcinogenic [12-14], estrogen-like effect [15-17], analgesic effect [10, 18], and impacts on enzymes $[5,17,19]$. However, it is well known that their bioavailabilities are poor, which restricted the fall use of flavonoids.

Phloretin is a flavonoid compound with its chemical structure (2',4',6'-trihydroxy-3-(4-hydroxyphenyl)-propiophenone, PHL, Figure 1) containing four phenolic hydroxyl. The unique chemical structure of PHL determines its strong antioxidant activity [20]. It can be found in apple tree leaves [21], pear, strawberries, and so on [22]. At present, PHL is used as a new type of cosmetic additives in many countries, because PHL may dilute the melanin and whiten the skin, and the effect is better than the present commonly used kojic acid and arbutin in cosmetics. In addition, PHL has a lot of biological activities, such as antioxidant $[20,23,24]$, hyperglycemic [25, 26], antitumor [27-29], and anti-inflammatory [30].

Despite the therapeutic effects of PHL, its pharmacokinetic properties are not favorable since this compound has poor bioavailability being rapidly and extensively metabolized. Some previous studies have shown that the poor bioavailability of flavonoids is mainly due to the wide range of phase II metabolism in vivo [31-33]. The phase II metabolites of flavonoids were subsequently rapidly excreted by the efflux transporters in the organism cells, resulting in the minimal amount of flavonoids

\footnotetext{
* Authors for correspondence: xyliu0427@163.com,wqwlxy@163.com
}

$\dagger$ These authors contributed equally to this work.<smiles>O=C(CCc1ccc(O)cc1)c1c(O)cc(O)cc1O</smiles>

A<smiles>CC(=O)Oc1ccc(CCC(=O)c2c(OC(C)=O)cc(OC(C)=O)cc2OC(C)=O)cc1</smiles>

B<smiles>Oc1ccc(/C=C/c2cc(O)cc(O)c2)cc1</smiles>

C
Figure 1. Chemical structures of PHL (A), TAPHL (B), and resveratrol (IS) (C)

that can be used. Although PHL has a very good pharmacological activity in vitro, it is limited by low bioavailability in vivo. Concurrently, the efficacy of orally administered PHL depends on its absorption, tissue distribution, metabolism, and excretion (ADME). Yang et al. [34] have found that acetylated hydroxyl groups did not undergo glucuronidation, and the modified compound exhibited a better pharmacokinetic profile. In order to improve the bioavailability of PHL, we protected the hydroxyl groups of PHL from metabolism by acetylating them and synthesized 2',4',6',4-tetra-O-acetylphloretin (TAPHL, Figure 1). As a prodrug of PHL, TAPHL is more stable than PHL in vitro, protecting phenolic hydroxy from being oxygenated. We still lack some basic knowledge of PHL and TAPHL, including its pharmacokinetics, tissue distribution, and excretion in vivo in experimental animal. Therefore, in the present study, we established a simple, sensitive, and rapid liquid chromatography-tandem

This is an open-access article distributed under the terms of the Creative Commons Attribution-NonCommercial 4.0 International License (https://creativecommons.org/licenses/by-nc/4.0/), which permits unrestricted use, distribution, and reproduction in any medium for non-commercial purposes, provided the original author and source are credited, a link to the CC License is provided, and changes - if any - are indicated. 
mass spectrometry (LC-MS/MS) method and validated for determination of PHL in rat biological samples using resveratrol as internal standard; meanwhile, it was successfully applied to investigate and compare the pharmacokinetics, tissue distribution, excretion of PHL, and TAPHL after oral administration in rats. TAPHL transformed into PHL in vivo, and we only detected PHL in ray plasma after oral administration of TAPHL to rats by LC-MS/MS. The causes and effects of the pharmacokinetics and distribution of TAPHL still require further study.

\section{Experimental}

2.1 Chemicals and Reagents. Phloretin (purity, $>99 \%$ ) and resveratrol (purity, $>99 \%$; internal standard, IS) were purchased from Xi'an Plants of Grass Technology Co. Ltd. (Shannxi, Xi'an, China). TAPHL was synthesized at the Department of Medicinal Chemistry, The Medical University of the Air Force and identified by infrared (IR), proton nuclear magnetic resonance ( $\left.{ }^{1} \mathrm{H}-\mathrm{NMR}\right)$, and high resolution mass spectrometry (HRMS) with purity greater than 99\%. Methanol, acetonitrile (Tedia Co. Inc., OH, USA), and analytical grade formic acid (Tianjin Fuyu Chemical, Tianjin, China) were of high-performance liquid chromatography (HPLC) grade. Milli-Q water was used throughout the whole experiments (Millipore, Bedford, MA, USA). Other solvents used for analysis were of analytical grade (Tianjin Fuyu Chemical, Tianjin, China).

2.2 Animals. Sprague-Dawley rats $(250 \pm 20 \mathrm{~g})$ were purchased from the Experimental Animal Center of the Medical University of the Air Force (Shaanxi, Xi'an, China) and acclimated in the laboratory for 1 week prior to the experiments, housed in separate cages at a temperature of $23 \pm 2{ }^{\circ} \mathrm{C}$ with a $12 \mathrm{~h}$ light-dark cycle and a relative humidity of $50 \%$, as well as free access to standard diet and water. All the rats were fasted for $12 \mathrm{~h}$ before the experiments with free access to water. The experimental protocol (20150701) involving animals was reviewed and approved by the Institutional Animal Care and Use Committee of the Medical University of the Air Force.

2.3 LC-MS/MS Assay. The liquid chromatography was performed on an Agilent 1260 Series liquid chromatography (Agilent Technologies, Palo Alto, CA, USA), which included an Agilent 1260 Quat pump VL, Agilent 1260 Autosampler, and temperature controlled column compartment. Chromatographic separation was achieved on Agilent Eclipse plus C18 column $(100 \mathrm{~mm} \times 2.1 \mathrm{~mm}, 3.5 \mu \mathrm{m})$ and maintained at $30{ }^{\circ} \mathrm{C}$. The mobile phase consisted of acetonitrile (contains $0.1 \%$ formic acid)water $(90: 10, \mathrm{v} / \mathrm{v})$ with fast isocratic elution at a flow rate of $0.6 \mathrm{~mL} / \mathrm{min}$ and run time of $5 \mathrm{~min}$. The sample volume injected was $5 \mu \mathrm{L}$, and the temperature of autosampler was set at $4{ }^{\circ} \mathrm{C}$.

The LC system was coupled with an Agilent $6460 \mathrm{C}$ triple quadrupole mass spectrometer (USA) equipped with an electrospray ionization source. The mass spectrometer was run in negative ion electrospray ionization (ESI) mode using multiple reaction monitoring (MRM) to monitor the mass transitions. The mass resolution was set at $0.7 \mu \mathrm{FWHM}$ (unit mass resolution) for both quadrupoles. Other parameters of the mass spectrometer were as follows: gas flow, $11.0 \mathrm{~L} / \mathrm{min}$; gas temperature, $350{ }^{\circ} \mathrm{C}$; sheath gas flow, $11.0 \mathrm{~L} / \mathrm{min}$; sheath gas temperature, $350{ }^{\circ} \mathrm{C}$; nebulizer, $40 \mathrm{psi}$; capillary, $4000 \mathrm{~V}$; chamber current, $0.30 \mu \mathrm{A}$. The MRM transitions were chosen to be $m / z 273.0 \rightarrow 166.8$ for PHL and $m / z 227.0 \rightarrow 142.9$ for IS. In the analytical condition, PHL and IS eluted at retention time of $1.83 \mathrm{~min}$ and $1.86 \mathrm{~min}$. The fragmentor voltage values set for PHL and IS were $110 \mathrm{~V}$ and $130 \mathrm{~V}$. The collision energy values set for PHL and IS were $10 \mathrm{eV}$ and $18 \mathrm{eV}$. Data were acquired and analyzed by the MassHunter QQQ Qualitative and Quantitative software (version B.06.00, Agilent Technologies, Inc., USA).

2.4 Preparation of Stock Solutions. Stock solutions $(1 \mathrm{mg} / \mathrm{mL})$ were prepared in methanol. These stock solutions were diluted with methanol to obtain calibration solutions (range, $10-50,000 \mathrm{ng} / \mathrm{mL}$ ). Internal standard solution was prepared by dilution of stock solution to a concentration of $50 \mathrm{ng} / \mathrm{mL}$. All the solutions were stored at $-20{ }^{\circ} \mathrm{C}$ and were brought to room temperature before use.

2.5 Plasma Kinetics. For the pharmacokinetic study, the rats were randomly divided into six groups ( $n=8$ per group). Phloretin which dissolved in $0.5 \%$ CMC-Na was orally administered at a single dose of 100,200 , and $300 \mathrm{mg} / \mathrm{kg}$ to three groups, respectively. We used ether to anesthetize rats before blood collection in whole experiments. $0.5 \mathrm{~mL}$ of blood samples was collected by retro-orbital puncture at 2, 5, $10,15,30,60,120,240,360,480$, and 720 min post-dosing. According to the principle of parallelism, the other three groups were orally administered of 160,320 , and $480 \mathrm{mg} / \mathrm{kg}$ TAPHL (equimolar with 100, 200, and $300 \mathrm{mg} / \mathrm{kg} \mathrm{PHL),}$ respectively. $0.5 \mathrm{~mL}$ of blood samples was collected by retroorbital puncture at $5,10,15,30,60,120,240,360,480,720$, and $1440 \mathrm{~min}$ post-dosing. Then, each blood sample was immediately centrifuged at approximately $2000 \mathrm{~g}, 4{ }^{\circ} \mathrm{C}$ for $15 \mathrm{~min}$, and a $100 \mu \mathrm{L}$ aliquot of supernatant plasma layer was transferred into another tube and stored at $-80{ }^{\circ} \mathrm{C}$ until analysis.

2.6 Tissue Distribution Study. For the tissue distribution study, the rats were randomly divided into eight groups $(n=6$ per group); four groups were orally administered at a single dose of PHL $(100 \mathrm{mg} / \mathrm{kg})$, and the other four groups were orally administered at a single dose of TAPHL $(160 \mathrm{mg} / \mathrm{kg})$. Then, the liver, heart, lung, spleen, kidney, stomach, brain, and intestine samples of former four groups were collected at $15,30,60$, and $120 \mathrm{~min}$ and those of latter four groups were collected at 15, 60, 240, and $480 \mathrm{~min}$, respectively. Tissues were flushed with physiological saline, dried, weighed, and then stored at $-80^{\circ} \mathrm{C}$ until analysis.

2.7 Excretion Study. For urinary and fecal excretion study, six rats received a single oral administration of PHL $(100 \mathrm{mg} / \mathrm{kg})$ and another six rats received a single oral administration of TAPHL $(160 \mathrm{mg} / \mathrm{kg})$. The rats were housed in stainless-steel metabolic cages with free access to water, and food was returned approximately $4 \mathrm{~h}$ post-dosing. Urine and feces were collected at $0-4,4-8,8-12,12-24$, and $24-36 \mathrm{~h}$ post-dosing. The feces were dried at $40{ }^{\circ} \mathrm{C}$ for $24 \mathrm{~h}$. The specimens were stored at $-80{ }^{\circ} \mathrm{C}$ after the urine volume and fecal dry weight for each collection period were measured.

2.8 Sample Preparation. An aliquot of $100 \mu \mathrm{L}$ rat plasma sample was mixed with $10 \mu \mathrm{L}$ of IS solution $(50 \mathrm{ng} / \mathrm{mL})$. One milliliter of ethyl acetate was added into the sample, and the mixture was vigorously stirred for $3 \mathrm{~min}$, which was followed by centrifugation at $2000 \mathrm{~g}$ for $10 \mathrm{~min}$. Finally, $800 \mu \mathrm{L}$ of upper organic phase was transferred to another tube and evaporated to dryness at $40{ }^{\circ} \mathrm{C}$ with nitrogen. The resulting extract was dissolved in $80 \mu \mathrm{L}$ of methanol and vortex-mixed for $3 \mathrm{~min}$. After centrifugation at $2000 \mathrm{~g}$ for $10 \mathrm{~min}, 5 \mu \mathrm{L}$ supernatant was injected into LC-MS.

Each weighed tissue sample was thawed and then homogenized in ice-cold physiological saline $(1: 4, \mathrm{w} / \mathrm{v})$. Then, a $100 \mathrm{~mL}$ of tissue homogenate was taken and processed further like the plasma samples. The feces samples were pulverized with a mortar and pestle. Physiological saline (1:4, w/v) was added and homogenized with the pulverized feces. Urine and feces samples were all processed in a similar manner as the plasma samples.

\subsection{Method Validation}

2.9.1 Selectivity. The selectivity of the method was evaluated by analyzing six individual sources of blank biological samples, blank biological matrix samples spiked with PHL, and actual biological matrix samples after oral administration of PHL or TAPHL, respectively. 
2.9.2 Linearity and Sensitivity. Linearity was analyzed by the weighted regression method $\left(1 / x^{2}\right)$ of peak area ratios of PHL to IS versus actual concentrations. The lower limit of quantification (LLOQ) was defined as the lowest concentration that could be determined with both accuracy and precision. The intra-day precision (relative standard deviation [RSD], \%) at LLOQ should not exceed 20\%, and the accuracy (relative error [RE] \%) should be within $\pm 20 \%$.

2.9.3 Accuracy and Precision. Accuracy and precision were evaluated in six replicates at three different concentrations (high, medium, low) on the same day and three analytical batches on three consecutive day using calibration curve, respectively. The accuracy was expressed by the RE and the precision by RSD. The accuracy should be within $\pm 15 \%$, and the intra-day and inter-day precision should not exceed $15 \%$.

2.9.4 Extraction Recovery and Matrix Effect. The extraction recovery of PHL and IS from biological matrices was evaluated by comparing the response of the extracted (pre-spiked) quality control (QC) samples with those of the unextracted biological samples at an equivalent concentration. The extraction recovery of PHL was determined at three different concentrations (high, medium, low), while IS at a single concentration of $50 \mathrm{ng} /$ $\mathrm{mL}$. The recovery was expressed by the mean \pm standard deviation (mean $\pm \mathrm{SD}$ ). The matrix effect was evaluated by comparing the response of the unextracted standard biological samples with those of neat samples at an equivalent concentration. The matrix effect was determined at three different concentrations (high, medium, low) and expressed by mean \pm SD. The assessment of a relative matrix effect was performed based on direct comparison of the responses (peak areas) of the analyte spiked into extracts originating from six different lots (sources) of biofluids. The variability in these responses, determined as RSD (\%), was considered as measure of relative matrix effect for a given analyte.

2.9.5 Stability. The stability of PHL in rat biological samples was evaluated by six replicates at three different concentrations (high, medium, low). The short-term stability was examined by keeping the replicates of samples at room temperature for $12 \mathrm{~h}$. The long-term stability was assessed by carrying out the experiment after 30 days of storage at $-20{ }^{\circ} \mathrm{C}$. Freeze-thaw stability was assessed over three freeze-thaw cycles. Post-preparation stability was assessed by analyzing the extracted samples kept in the autosampler at $4{ }^{\circ} \mathrm{C}$ for $24 \mathrm{~h}$.

2.10 Statistical Analysis. The LC-MS/MS procedure developed here was used to investigate all of the biological matrices (plasma, liver, heart, lung, spleen, kidney, stomach, brain, intestine, urine, and feces) of PHL after oral administration. The concentration versus time profiles were obtained for each individual rat, and non-compartmental pharmacokinetic modeling and pharmacokinetic parameter calculation were performed using the DAS Software (version 2.0, Anhui Provincial Center for Drug Clinical Evaluation, China). Dose-proportionality after a single oral administration of different dosages was determined by comparison of the dose-normalized $\mathrm{AUC}_{0}-\infty$ across dosage levels using the SPSS 13.0 one-way analysis of variance (ANOVA) and linear
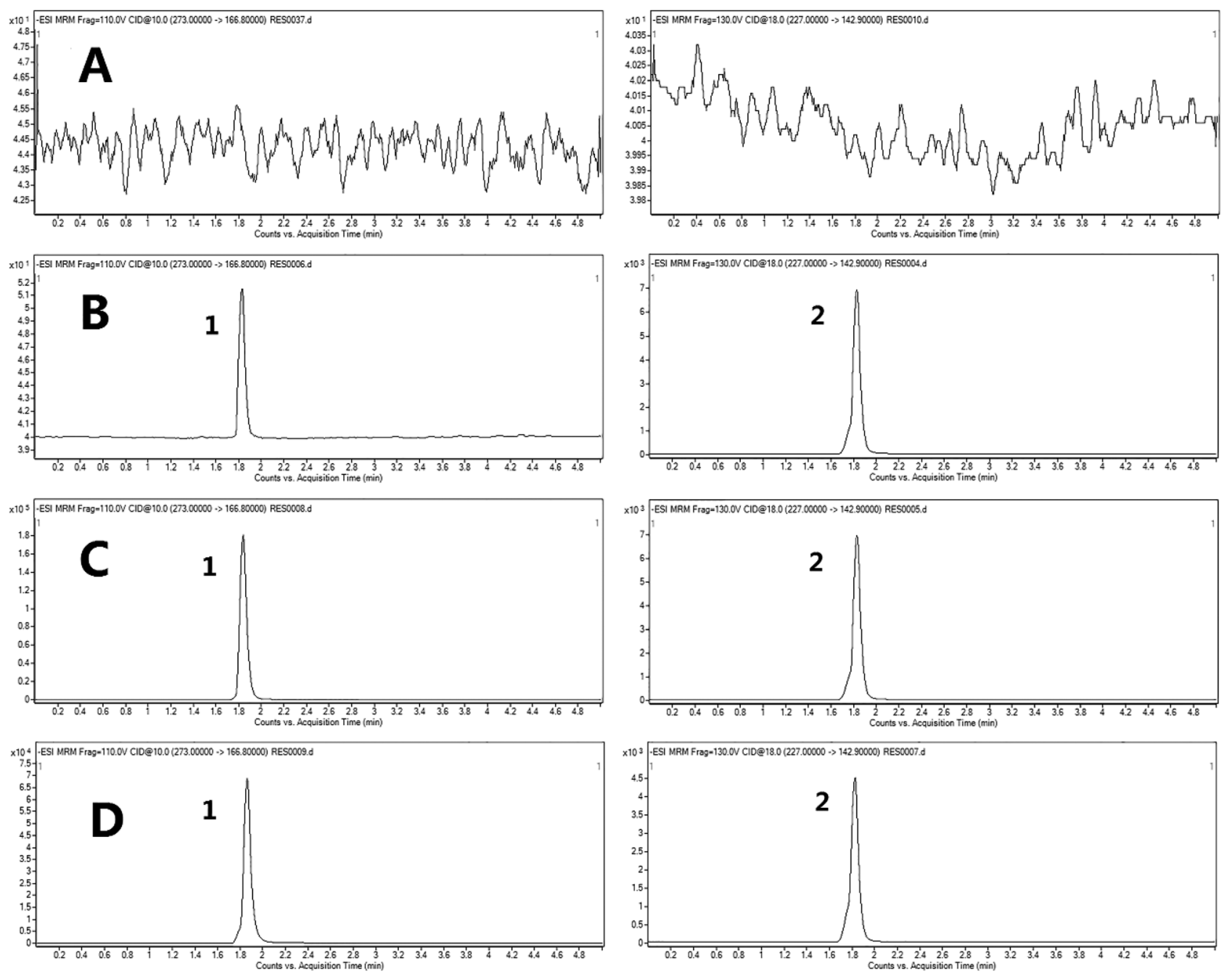

Figure 2. Representative MRM chromatograms for PHL and IS: (A) a blank plasma sample; (B) a blank plasma sample spiked with PHL (10 ng/mL) and IS $(50 \mathrm{ng} / \mathrm{mL}) ;(C)$ a plasma sample from a rat $30 \mathrm{~min}$ after an oral administration of PHL $(100 \mathrm{mg} / \mathrm{kg})$; (D) a plasma sample from a rat $30 \mathrm{~min}$ after an oral administration of TAPHL $(160 \mathrm{mg} / \mathrm{kg})$. Peak 1 , PHL $\left(t_{\mathrm{R}}=1.83 \mathrm{~min}\right)$; peak 2 , IS $\left(t_{\mathrm{R}}=1.86 \mathrm{~min}\right)$ 
regression analysis. All the data are expressed as mean $\pm \mathrm{SD}$, and a $P$ value of $<0.05$ was deemed to be statistically significant.

\section{Results}

3.1 Method Development and Optimization. The internal standard should have similar chromatographic and mass spectrometric behavior to the analyte; resveratrol was selected as the IS for the quantification of PHL because of its similarity of chemical structure, retention action, and ionization. The ion abundances of PHL and IS were significantly greater in negativeion mode than in positive-ion mode. Additionally, the MRM transitions were chosen to be $\mathrm{m} / z 273.0 \rightarrow 166.8$ for PHL and $\mathrm{m} / \mathrm{z} 227.0 \rightarrow 142.9$ for IS. Acetonitrile was selected as the organic portion of the mobile phase; it was found that the addition of $0.1 \%$ formic acid in the organic phase could enhance the sensitivity and improve the peak shapes of PHL and IS. Several attempts were made with different C18 HPLC columns; the best chromatographic separation and response were achieved on Agilent Eclipse plus C18 column $(100 \mathrm{~mm} \times 2.1 \mathrm{~mm}, 3.5 \mu \mathrm{m})$.

\subsection{Method Validation}

3.2.1 Selectivity. The validated method was highly selective for the analytes as no significant interference was observed at the corresponding retention time in the blank plasma samples from six different batches. Figure 2 shows the typical chromatograms of a blank plasma sample, a blank plasma sample spiked with PHL and IS, a plasma sample from a rat $30 \mathrm{~min}$ after oral administration of PHL $(100 \mathrm{mg} / \mathrm{kg})$, and a plasma sample from a rat $30 \mathrm{~min}$ after oral administration of TAPHL $(160 \mathrm{mg} / \mathrm{kg})$. Under the given condition, PHL and IS eluted at retention time of $1.83 \mathrm{~min}$ and $1.86 \mathrm{~min}$. The result demonstrated that there was no interference with the determination of the PHL and IS, granting good method selectivity.

Table 1. Precision and accuracy for the analysis of PHL in biological samples ( $n=3$ days, six replicates per day)

\begin{tabular}{|c|c|c|c|c|c|}
\hline \multirow{2}{*}{$\begin{array}{l}\text { Biological } \\
\text { sample }\end{array}$} & \multirow{2}{*}{$\begin{array}{l}\text { Added concentration } \\
(\mathrm{ng} / \mathrm{mL})\end{array}$} & \multicolumn{2}{|c|}{ Intra-day } & \multicolumn{2}{|c|}{ Inter-day } \\
\hline & & RSD (\%) & RE (\%) & RSD (\%) & RE (\%) \\
\hline \multirow[t]{3}{*}{ Plasma } & 10 & 2.7 & 5.6 & 1.8 & 3.9 \\
\hline & 2000 & 2.0 & 3.5 & 3.4 & 5.4 \\
\hline & 50,000 & 1.7 & 4.5 & 4.9 & 3.4 \\
\hline \multirow[t]{3}{*}{ Liver } & 10 & 0.8 & 3.3 & 2.0 & -2.7 \\
\hline & 2000 & 3.7 & 3.8 & 3.4 & 4.8 \\
\hline & 50,000 & 3.8 & -5.3 & 4.6 & -4.4 \\
\hline \multirow[t]{3}{*}{ Heart } & 10 & 4.9 & 2.5 & 6.1 & 3.6 \\
\hline & 2000 & 5.5 & 6.6 & 4.9 & 7.5 \\
\hline & 50,000 & 4.0 & 7.5 & 5.6 & 5.6 \\
\hline \multirow[t]{3}{*}{ Lung } & 10 & 3.0 & 6.6 & 6.5 & 6.5 \\
\hline & 2000 & 3.8 & 1.6 & 5.0 & -5.1 \\
\hline & 50,000 & 2.0 & -4.8 & 2.4 & 5.6 \\
\hline \multirow[t]{3}{*}{ Spleen } & 10 & 4.7 & 5.0 & 3.3 & -6.0 \\
\hline & 2000 & 8.0 & -2.8 & 7.1 & 3.6 \\
\hline & 50,000 & 4.5 & 2.3 & 3.9 & -4.0 \\
\hline \multirow[t]{3}{*}{ Kidney } & 10 & 4.9 & 4.8 & 5.5 & 5.5 \\
\hline & 2000 & 4.4 & 3.5 & 3.9 & -2.9 \\
\hline & 50,000 & 6.1 & -0.8 & 6.9 & 4.8 \\
\hline \multirow[t]{3}{*}{ Stomach } & 10 & 5.6 & 2.5 & 6.1 & 6.1 \\
\hline & 2000 & 3.4 & 7.6 & 6.8 & -2.2 \\
\hline & 50,000 & 3.9 & 2.5 & 2.8 & 3.6 \\
\hline \multirow[t]{3}{*}{ Brain } & 10 & 4.9 & 3.3 & 4.4 & 5.4 \\
\hline & 2000 & 6.7 & -4.5 & 8.0 & 6.4 \\
\hline & 50,000 & 5.7 & 5.4 & 4.6 & 3.8 \\
\hline \multirow[t]{3}{*}{ Intestine } & 10 & 4.1 & -4.7 & 5.9 & -5.4 \\
\hline & 2000 & 2.0 & 3.9 & 4.3 & 3.8 \\
\hline & 50,000 & 1.7 & -3.8 & 5.4 & 4.5 \\
\hline \multirow[t]{3}{*}{ Urine } & 10 & 5.3 & 3.1 & 4.2 & 6.7 \\
\hline & 2000 & 4.1 & 2.9 & 3.8 & 5.1 \\
\hline & 50,000 & 2.4 & 2.6 & 3.4 & -3.7 \\
\hline \multirow[t]{3}{*}{ Feces } & 10 & 7.0 & 6.4 & 7.7 & 8.5 \\
\hline & 2000 & 5.9 & -4.7 & 5.0 & 7.0 \\
\hline & 50,000 & 3.9 & 4.1 & 3.2 & 5.7 \\
\hline
\end{tabular}

3.2.2 Linearity and Sensitivity. The standard calibration curve for spiked rat biological samples containing PHL was linear over the range of $10-50,000 \mathrm{ng} / \mathrm{mL}$. The calibration curves for all biological samples showed good linearity $\left(r^{2}>0.9965\right)$ over the concentration ranges tested. The LLOQ was $10 \mathrm{ng} / \mathrm{mL}$, which was sensitive enough for the pharmacokinetic, tissue distribution, and excretion study of PHL for oral administration in rats.

3.2.3 Accuracy and Precision. The intra-day and inter-day precision and accuracy were shown in Table 1. The accuracy and precision of within-run and between-run should be within $15 \%$ of the nominal values, except for the LLOQ which should be within $20 \%$ of the nominal value. This indicated that the method was accurate and precise over the range of the assay.

3.2.4 Extraction Recovery and Matrix Effect. Table 2 illustrates the recoveries of PHL at three concentration levels and the recovery of IS. The results indicate that the extraction recovery of this method was consistent, reproducible, and acceptable. Matrix effects on recovery of blank biological samples spiked after the sample preparation with 10, 2000, and $50,000 \mathrm{ng} / \mathrm{mL}$ of all analytes was found to be within the acceptable limits. The same evaluation was performed on the IS (50 ng/mL), and no significant peak area differences were detected. Thus, it was demonstrated that the matrix effect was negligible for the assay.

3.2.5 Stability. The stability of PHL was studied under a variety of storage and handling conditions. Table 3 shows that the rat biological samples were stable at $-20{ }^{\circ} \mathrm{C}$ for at least 30 days with no significant loss. Biological samples were stable over at least three freeze-thaw cycles. Otherwise, the results of the pre-test revealed that TAPHL had good stability after leaving untreated in rat plasma at room temperature for $24 \mathrm{~h}$. TAPHL was also stable in rat human plasma $\left(-80^{\circ} \mathrm{C}\right)$ for 180 days.

Table 2. Recovery and matrix effect of PHL in biological samples $(n=6)$

\begin{tabular}{|c|c|c|c|c|c|}
\hline \multirow{2}{*}{$\begin{array}{l}\text { Biological } \\
\text { sample }\end{array}$} & \multirow{2}{*}{$\begin{array}{c}\text { Added } \\
\text { concentration } \\
(\mathrm{ng} / \mathrm{mL})\end{array}$} & \multicolumn{2}{|l|}{ Recovery } & \multicolumn{2}{|c|}{ Matrix effect } \\
\hline & & $($ Mean \pm SD $\%)$ & $\begin{array}{c}\text { RSD } \\
(\%)\end{array}$ & $($ Mean $\pm \mathrm{SD} \%)$ & $\begin{array}{l}\text { RSD } \\
(\%)\end{array}$ \\
\hline \multirow[t]{3}{*}{ Plasma } & 10 & $97.7 \pm 7.4$ & 7.9 & $98.6 \pm 6.9$ & 6.7 \\
\hline & 2000 & $98.3 \pm 5.1$ & 5.6 & $106.7 \pm 3.2$ & 3.6 \\
\hline & 50,000 & $98.1 \pm 1.0$ & 1.2 & $104.1 \pm 4.6$ & 4.2 \\
\hline \multirow[t]{3}{*}{ Liver } & 10 & $10.3 .1 \pm 5.6$ & 5.6 & $94.1 \pm 3.4$ & 2.9 \\
\hline & 2000 & $99.4 \pm 4.3$ & 3.9 & $93.4 \pm 0.4$ & 0.4 \\
\hline & 50,000 & $95.4 \pm 4.5$ & 4.5 & $97.1 \pm 6.5$ & 6.9 \\
\hline \multirow[t]{3}{*}{ Heart } & 10 & $97.4 \pm 7.5$ & 8.0 & $99.1 \pm 4.8$ & 4.4 \\
\hline & 2000 & $96.4 \pm 2.4$ & 2.0 & $105.4 \pm 6.4$ & 6.0 \\
\hline & 50,000 & $104.2 \pm 4.6$ & 4.3 & $94.6 \pm 3.8$ & 3.6 \\
\hline \multirow[t]{3}{*}{ Lung } & 10 & $97.9 \pm 6.4$ & 4.8 & $99.2 \pm 4.3$ & 5.5 \\
\hline & 2000 & $94.3 \pm 5.5$ & 4.0 & $93.6 \pm 3.5$ & 3.8 \\
\hline & 50,000 & $98.2 \pm 7.4$ & 3.8 & $97.7 \pm 7.4$ & 4.6 \\
\hline \multirow[t]{3}{*}{ Spleen } & 10 & $93.6 \pm 6.7$ & 4.7 & $95.3 \pm 3.0$ & 6.1 \\
\hline & 2000 & $100.6 \pm 5.4$ & 5.4 & $99.7 \pm 5.6$ & 7.5 \\
\hline & 50,000 & $95.4 \pm 3.2$ & 4.2 & $97.6 \pm 4.8$ & 5.7 \\
\hline \multirow[t]{3}{*}{ Kidney } & 10 & $94.5 \pm 4.6$ & 7.5 & $102.5 \pm 3.7$ & 3.3 \\
\hline & 2000 & $106.1 \pm 5.6$ & 5.6 & $97.7 \pm 4.9$ & 6.9 \\
\hline & 50,000 & $98.4 \pm 3.8$ & 6.5 & $94.6 \pm 8.4$ & 5.9 \\
\hline \multirow[t]{3}{*}{ Stomach } & 10 & $103.4 \pm 7.1$ & 5.7 & $100.6 \pm 6.7$ & 7.2 \\
\hline & 2000 & $94.8 \pm 3.1$ & 2.8 & $99.1 \pm 4.5$ & 8.0 \\
\hline & 50,000 & $96.4 \pm 4.3$ & 5.8 & $103.4 \pm 2.5$ & 4.4 \\
\hline \multirow[t]{3}{*}{ Brain } & 10 & $98.6 \pm 6.1$ & 6.8 & $104.6 \pm 1.8$ & 7.1 \\
\hline & 2000 & $105.1 \pm 4.7$ & 5.5 & $98.6 \pm 5.7$ & 4.9 \\
\hline & 50,000 & $99.4 \pm 1.5$ & 1.7 & $99.1 \pm 4.4$ & 4.5 \\
\hline \multirow[t]{3}{*}{ Intestine } & 10 & $95.8 \pm 6.2$ & 5.8 & $101.6 \pm 3.4$ & 4.0 \\
\hline & 2000 & $98.7 \pm 1.9$ & 2.1 & $96.8 \pm 2.6$ & 2.4 \\
\hline & 50,000 & $102.4 \pm 2.4$ & 1.8 & $95.7 \pm 4.8$ & 4.9 \\
\hline \multirow[t]{3}{*}{ Urine } & 10 & $99.4 \pm 7.6$ & 7.4 & $104.8 \pm 7.5$ & 7.7 \\
\hline & 2000 & $98.5 \pm 6.1$ & 6.5 & $98.0 \pm 7.4$ & 5.7 \\
\hline & 50,000 & $96.4 \pm 4.4$ & 4.3 & $98.7 \pm 9.8$ & 8.7 \\
\hline \multirow[t]{3}{*}{ Feces } & 10 & $93.4 \pm 1.2$ & 0.9 & $92.7 \pm 3.9$ & 4.2 \\
\hline & 2000 & $99.2 \pm 5.8$ & 4.6 & $97.1 \pm 6.2$ & 6.4 \\
\hline & 50,000 & $96.2 \pm 3.8$ & 4.2 & $98.6 \pm 4.7$ & 3.9 \\
\hline
\end{tabular}


Table 3. Stability of PHL in biological samples $(n=6)$

\begin{tabular}{|c|c|c|c|c|c|}
\hline $\begin{array}{l}\text { Biological } \\
\text { sample }\end{array}$ & $\begin{array}{l}\text { Added concentration } \\
(\mathrm{ng} / \mathrm{mL})\end{array}$ & $\begin{array}{l}\text { Frozen for } 30 \mathrm{~d} \\
(\text { Mean } \pm \mathrm{SD} \%)\end{array}$ & $\begin{array}{l}\text { Three freeze-thaw cycles } \\
\quad(\text { Mean } \pm \mathrm{SD} \%)\end{array}$ & $\begin{array}{l}\text { Room temperature for } 12 \mathrm{~h} \\
\quad(\text { Mean } \pm \mathrm{SD} \%)\end{array}$ & $\begin{array}{l}\text { Prepared samples in freezer } \\
\left(-20^{\circ} \mathrm{C}\right) \text { for } 24 \mathrm{~h} \\
\left(\text { Mean } \pm \mathrm{SD}^{2}\right)\end{array}$ \\
\hline \multirow[t]{3}{*}{ Plasma } & 10 & $105.3 \pm 3.6$ & $96.2 \pm 4.6$ & $95.4 \pm 0.4$ & $104.7 \pm 5.4$ \\
\hline & 2000 & $99.5 \pm 6.4$ & $97.4 \pm 4.1$ & $103.5 \pm 7.4$ & $102.9 \pm 5.3$ \\
\hline & 50,000 & $97.5 \pm 7.1$ & $96.8 \pm 5.4$ & $98.4 \pm 5.2$ & $98.3 \pm 7.4$ \\
\hline \multirow[t]{3}{*}{ Liver } & 10 & $104.3 \pm 5.1$ & $98.5 \pm 6.3$ & $102.4 \pm 4.9$ & $105.2 \pm 6.1$ \\
\hline & 2000 & $99.1 \pm 0.6$ & $103.1 \pm 2.5$ & $94.7 \pm 4.3$ & $98.6 \pm 4.2$ \\
\hline & 50,000 & $96.7 \pm 6.8$ & $98.4 \pm 2.5$ & $97.6 \pm 4.5$ & $102.4 \pm 3.8$ \\
\hline \multirow[t]{3}{*}{ Heart } & 10 & $101.6 \pm 5.1$ & $95.4 \pm 6.1$ & $98.7 \pm 4.8$ & $105.7 \pm 1.9$ \\
\hline & 2000 & $96.5 \pm 4.3$ & $98.1 \pm 5.3$ & $96.4 \pm 3.2$ & $99.2 \pm 2.7$ \\
\hline & 50,000 & $103.9 \pm 2.5$ & $105.4 \pm 2.3$ & $96.7 \pm 5.1$ & $97.0 \pm 6.5$ \\
\hline \multirow[t]{3}{*}{ Lung } & 10 & $98.8 \pm 3.6$ & $94.8 \pm 6.8$ & $100.6 \pm 3.1$ & $95.4 \pm 3.6$ \\
\hline & 2000 & $92.7 \pm 4.6$ & $99.3 \pm 3.5$ & $93.7 \pm 1.3$ & $102.6 \pm 4.5$ \\
\hline & 50,000 & $99.4 \pm 5.4$ & $104.6 \pm 5.9$ & $101.4 \pm 6.5$ & $103.1 \pm 5.7$ \\
\hline \multirow[t]{3}{*}{ Spleen } & 10 & $93.7 \pm 5.8$ & $96.5 \pm 1.6$ & $97.5 \pm 5.6$ & $96.5 \pm 5.3$ \\
\hline & 2000 & $95.1 \pm 6.1$ & $99.4 \pm 5.0$ & $103.6 \pm 7.4$ & $93.0 \pm 6.2$ \\
\hline & 50,000 & $100.5 \pm 2.3$ & $95.3 \pm 6.0$ & $106.3 \pm 4.3$ & $105.2 \pm 1.2$ \\
\hline \multirow[t]{3}{*}{ Kidney } & 10 & $97.4 \pm 6.1$ & $98.0 \pm 5.3$ & $98.4 \pm 4.8$ & $95.6 \pm 5.4$ \\
\hline & 2000 & $92.1 \pm 5.4$ & $99.7 \pm 4.6$ & $97.0 \pm 2.1$ & $103.6 \pm 2.4$ \\
\hline & 50,000 & $105.4 \pm 6.3$ & $105.4 \pm 2.2$ & $98.6 \pm 2.4$ & $99.4 \pm 2.5$ \\
\hline \multirow[t]{3}{*}{ Stomach } & 10 & $101.3 \pm 3.1$ & $95.3 \pm 4.3$ & $99.8 \pm 7.2$ & $96.6 \pm 4.5$ \\
\hline & 2000 & $100.5 \pm 3.7$ & $97.6 \pm 4.7$ & $98.4 \pm 3.5$ & $97.5 \pm 2.2$ \\
\hline & 50,000 & $99.4 \pm 4.2$ & $92.4 \pm 7.1$ & $98.5 \pm 3.3$ & $100.5 \pm 4.3$ \\
\hline \multirow[t]{3}{*}{ Brain } & 10 & $100.8 \pm 3.1$ & $103.5 \pm 6.4$ & $100.4 \pm 0.3$ & $104.5 \pm 6.2$ \\
\hline & 2000 & $99.4 \pm 3.1$ & $105.4 \pm 1.4$ & $94.6 \pm 6.1$ & $100.4 \pm 4.6$ \\
\hline & 50,000 & $103.4 \pm 5.4$ & $97.5 \pm 6.2$ & $99.1 \pm 3.2$ & $99.4 \pm 3.3$ \\
\hline \multirow[t]{3}{*}{ Intestine } & 10 & $98.4 \pm 0.7$ & $96.1 \pm 5.1$ & $97.2 \pm 4.7$ & $93.2 \pm 3.7$ \\
\hline & 2000 & $103.6 \pm 1.3$ & $98.4 \pm 3.3$ & $96.1 \pm 3.8$ & $101.3 \pm 2.3$ \\
\hline & 50,000 & $97.5 \pm 4.5$ & $104.6 \pm 2.5$ & $98.6 \pm 4.7$ & $99.4 \pm 2.7$ \\
\hline \multirow[t]{3}{*}{ Urine } & 10 & $106.4 \pm 2.6$ & $95.4 \pm 5.6$ & $95.4 \pm 0.4$ & $104.7 \pm 5.4$ \\
\hline & 2000 & $99.5 \pm 6.4$ & $97.4 \pm 4.1$ & $103.5 \pm 7.4$ & $102.9 \pm 5.3$ \\
\hline & 50,000 & $97.5 \pm 7.1$ & $96.8 \pm 5.4$ & $98.4 \pm 5.2$ & $98.3 \pm 7.4$ \\
\hline \multirow[t]{3}{*}{ Feces } & 10 & $104.3 \pm 5.1$ & $98.5 \pm 6.3$ & $102.4 \pm 4.9$ & $105.2 \pm 6.1$ \\
\hline & 2000 & $99.1 \pm 0.6$ & $103.1 \pm 2.5$ & $94.7 \pm 4.3$ & $98.6 \pm 4.2$ \\
\hline & 50,000 & $96.7 \pm 6.8$ & $98.4 \pm 2.5$ & $97.6 \pm 4.5$ & $102.4 \pm 3.8$ \\
\hline
\end{tabular}

3.3 Pharmacokinetic Study. The LC-MS/MS method was successfully applied to investigate the pharmacokinetics of PHL following oral administration of PHL and TAPHL. In the study, we compared the pharmacokinetic parameters of rats which were administered PHL and TAPHL. Mean plasma concentration-time curves $(n=8)$ were presented in Figure 3. The main pharmacokinetic parameters calculated using non-compartmental analysis were shown in Tables 4 and 5.

3.4 Tissue Distribution Study. Tissue distribution of PHL and TAPHL was investigated following oral administration of a single dose at $100 \mathrm{mg} / \mathrm{kg}$ and $160 \mathrm{mg} / \mathrm{kg}$. Concentrations of PHL were determined in various tissues of rat such as liver, heart, lung, spleen, kidney, stomach, brain, and intestine, respectively. Figure 4 shows the concentrations of PHL in rat tissues collected at $15,30,60$, and $120 \mathrm{~min}$ after oral administration of PHL and 15, 60, 240, and 480 min after oral administration of TAPHL.

3.5 Excretion Study. The excretion of PHL and TAPHL in urine and feces was illustrated in Figure 5.

\section{Discussion}

It is generally known that PHL in vivo is hindered by its rapid transformation via phase II conjugative metabolism [20]. In order to improve the bioavailability of PHL, we protected the hydroxyl groups of PHL from metabolism by acetylating them and synthesized TAPHL. Comparing the abundant pharmacological studies, few reports were related to the pharmacokinetics, tissue distribution, and excretion study of PHL. However, pharmacokinetic study is an effective method to predict and explain compound related to the efficacy and toxicity in preclinical and clinical trials. To the best of our knowledge, there is no available integrated data on the tissue distribution and excretion study of PHL after oral administration in rats. In this study, we examined and compared the pharmacokinetics and tissue distribution of TAPHL with those of PHL in rats by taking advantage of LC-MS/MS.

Significant differences of $t_{\max }, C_{\max }, \mathrm{AUC}_{(0-t)}$, and $\mathrm{CL} / \mathrm{F}$ were observed after equimolar dose of PHL and TAPHL oral administration. The results indicated that the concentrationtime $(\mathrm{C}-\mathrm{T})$ curves of different dosages accorded with firstorder linear equation. As seen in Figure 3 and Tables 4 and 5, after oral administration of 100,200 , and $300 \mathrm{mg} / \mathrm{kg}$, PHL which could be detected just for $2 \mathrm{~min}$, was absorbed and eliminated rapidly from plasma. However, $t_{1 / 2}$ was nearly $6 \mathrm{~h}$ which revealed that the residence time of PHL was not short, which might have some relationships with its chemical structure and the physicochemical property. After oral administration of TAPHL to rats, AUC and $t_{\max }$ increased among the three dosages; meanwhile, $C_{\max }$ of the three dosages decreased. However, there were no significant differences in other pharmacokinetic parameters such as $\mathrm{AUC}_{(0-\infty)}$ in highest dosages, $t_{1 / 2}, \mathrm{CL}$, and $\mathrm{Vz}$ among the three dosages analyzed by ANOVA $(P>0.05)$. The results indicated that TAPHL could effectively increase the bioavailability and extend the duration of action of PHL.

The data indicated that different levels of PHL were observed in most of the tissues at 15 min whether oral administration of PHL or TAPHL to rats. In addition, the concentration of PHL in the stomach and intestinal was significantly higher than that in other organizations after $30 \mathrm{~min}$, accounting for about $90 \%$ of the organization's total drug content. The concentrations of PHL gradually decreased in stomach for about $60 \mathrm{~min}$. It increased in the heart, liver, lung, and kidney, especially in the liver and lung. In 

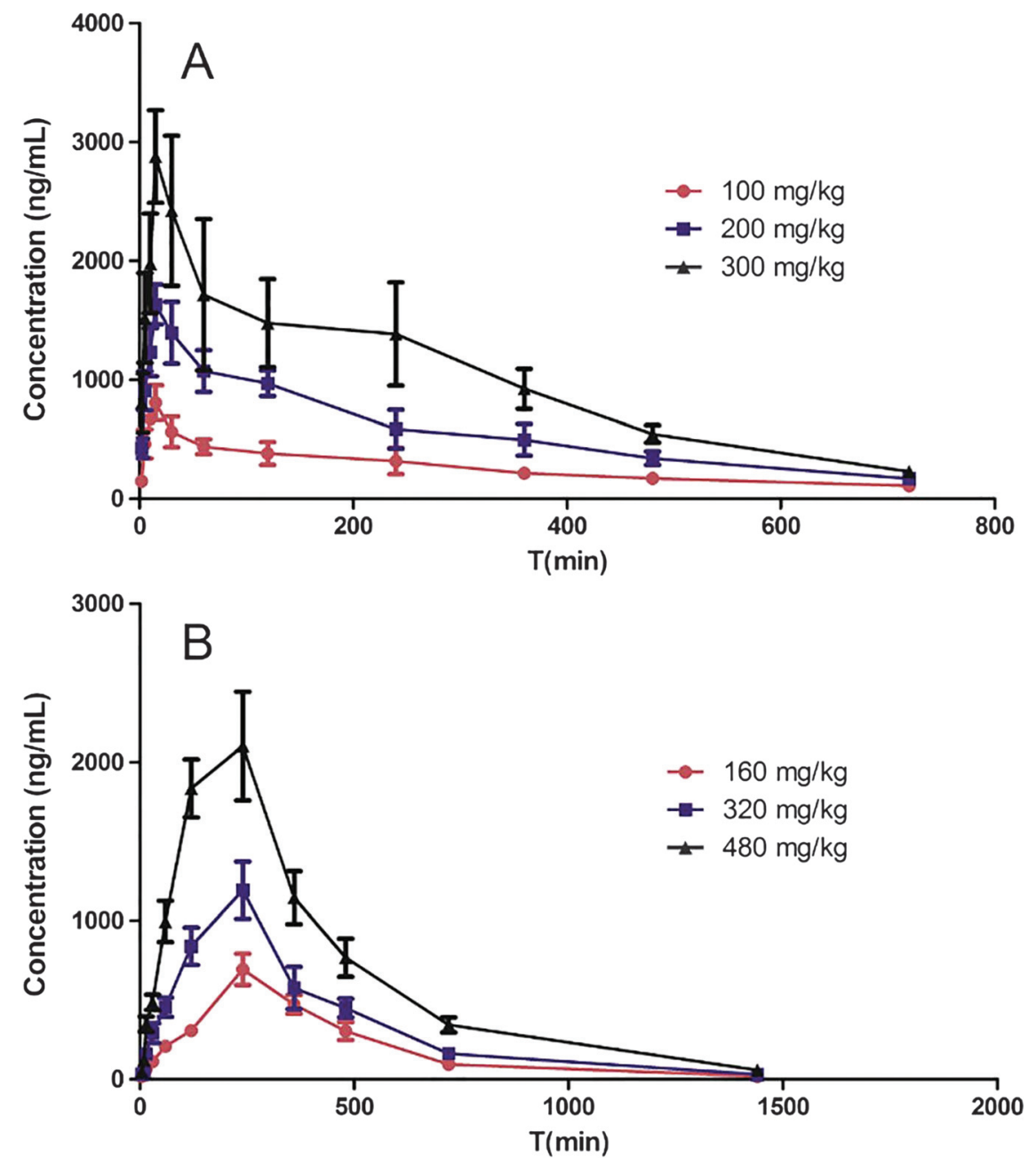

Figure 3. Mean plasma concentration-time curves (mean $\pm \mathrm{SD}, n=8$ ) of PHL after oral administration of $100 \mathrm{mg} / \mathrm{kg}, 200 \mathrm{mg} / \mathrm{kg}$, and $300 \mathrm{mg} / \mathrm{kg}$ PHL (A) and $160 \mathrm{mg} / \mathrm{kg}, 320 \mathrm{mg} / \mathrm{kg}$, and $480 \mathrm{mg} / \mathrm{kg}$ TAPHL (B) to rats

addition, when the concentration showed a downward trend after $120 \mathrm{~min}$, the concentration of drug in lung continually rise, which was mostly up to half of the organization's total drug content. Phloretin was not detected in brain, which indicated that PHL had difficulty in crossing the BBB (bloodbrain barrier). The peak levels in most tissues coincided with that in plasma, which implied that the distribution of PHL was depended on the blood flow or perfusion rate of the organ. In addition, its tissue distribution after oral administration of TAPHL to rats was similar as that after oral administration of equimolar PHL.

After a single dose oral administration of $100 \mathrm{mg} / \mathrm{kg}$ PHL, the ratio of PHL in urine was $1.28 \%$ of the total and the ratio of that in feces was $0.95 \%$, which suggested that portions of PHL could be eliminated by transforming into other metabolites. Following oral administration of equimolar TAPHL, recoveries

Table 4. Pharmacokinetic parameters of PHL in rats after oral administration of $100 \mathrm{mg} / \mathrm{kg}, 200 \mathrm{mg} / \mathrm{kg}$, and $300 \mathrm{mg} / \mathrm{kg} \mathrm{PHL}$

\begin{tabular}{lcccc}
\hline Parameter & Unit & \multicolumn{3}{c}{ Administration of PHL } \\
\cline { 3 - 5 } & & $100 \mathrm{mg} / \mathrm{kg}$ & $200 \mathrm{mg} / \mathrm{kg}$ & $300 \mathrm{mg} / \mathrm{kg}$ \\
\hline $\mathrm{AUC}_{(0-t)}$ & $\mathrm{mg} / \mathrm{L} * \min$ & $141.5 \pm 34.3$ & $463.5 \pm 94.9$ & $780.4 \pm 201.5$ \\
$\mathrm{AUC}_{(0-\infty)}$ & $\mathrm{mg} / \mathrm{L} * \min$ & $219.8 \pm 57.4$ & $586.1 \pm 154.7$ & $1030.6 \pm 217.3$ \\
$t_{1 / 2}$ & $\mathrm{~min}$ & $241.4 \pm 77.6$ & $291.4 \pm 58.7$ & $238.4 \pm 71.11$ \\
$t_{\max }$ & $\mathrm{min}$ & $15.00 \pm 8.37$ & $16.67 \pm 6.83$ & $17.50 \pm 6.12$ \\
$\mathrm{CL} / \mathrm{F}$ & $\mathrm{L} / \mathrm{min} / \mathrm{kg}$ & $0.45 \pm 0.21$ & $0.43 \pm 0.16$ & $0.36 \pm 0.18$ \\
$C_{\max }$ & $\mathrm{ng} / \mathrm{mL}$ & $952 \pm 204$ & $1801 \pm 321$ & $3366 \pm 1286$ \\
\hline
\end{tabular}

of PHL in urine and feces within $36 \mathrm{~h}$ were about $1.91 \%$ and $2.01 \%$. The data indicated that few intact form of PHL was excreted by kidney, which might be resulted from liver first pass effect. Higher recoveries of PHL following administration of TAPHL indicated that TAPHL might reduce the excretion of PHL from the body by reducing the first pass effect.

\section{Conclusion}

To the best of our knowledge, this is the first report to evaluate the pharmacokinetics, tissue distribution, and excretion of TAPHL in rats after oral administration and compared its properties with those of its parent drug PHL. A validated LC-MS/MS method for the determination of PHL in rat biological matrices was developed and applied to investigate the pharmacokinetics and tissue distribution of PHL in rats. The

Table 5. Pharmacokinetic parameters of PHL in rats after oral administration of $160 \mathrm{mg} / \mathrm{kg}, 320 \mathrm{mg} / \mathrm{kg}$, and $480 \mathrm{mg} / \mathrm{kg}$ TAPHL

\begin{tabular}{lcccc}
\hline Parameter & Unit & \multicolumn{3}{c}{ Administration of TAPHL } \\
\cline { 3 - 5 } & & $160 \mathrm{mg} / \mathrm{kg}$ & $320 \mathrm{mg} / \mathrm{kg}$ & $480 \mathrm{mg} / \mathrm{kg}$ \\
\hline $\mathrm{AUC}_{(0-t)}$ & $\mathrm{mg} / \mathrm{L}^{*} \min$ & $287.8 \pm 74.8$ & $487.4 \pm 103.0$ & $939.8 \pm 141.1$ \\
$\mathrm{AUC}_{(0-\infty)}$ & $\mathrm{mg} / \mathrm{L}^{*} \min$ & $293.2 \pm 78.1$ & $695.2 \pm 100.6$ & $1063.4 \pm 148.9$ \\
$t_{1 / 2}$ & $\mathrm{~min}$ & $195.5 \pm 75.7$ & $291.4 \pm 58.7$ & $268.0 \pm 69.1$ \\
$t_{\max }$ & $\mathrm{min}$ & $260.00 \pm 48.99$ & $226.40 \pm 68.98$ & $220.00 \pm 90.33$ \\
$\mathrm{CL} / \mathrm{F}$ & $\mathrm{L} / \mathrm{min} / \mathrm{kg}$ & $0.36 \pm 0.10$ & $0.42 \pm 0.01$ & $0.32 \pm 0.06$ \\
$C_{\max }$ & $\mathrm{ng} / \mathrm{mL}$ & $726 \pm 176$ & $1193 \pm 441$ & $2325 \pm 655$ \\
\hline
\end{tabular}



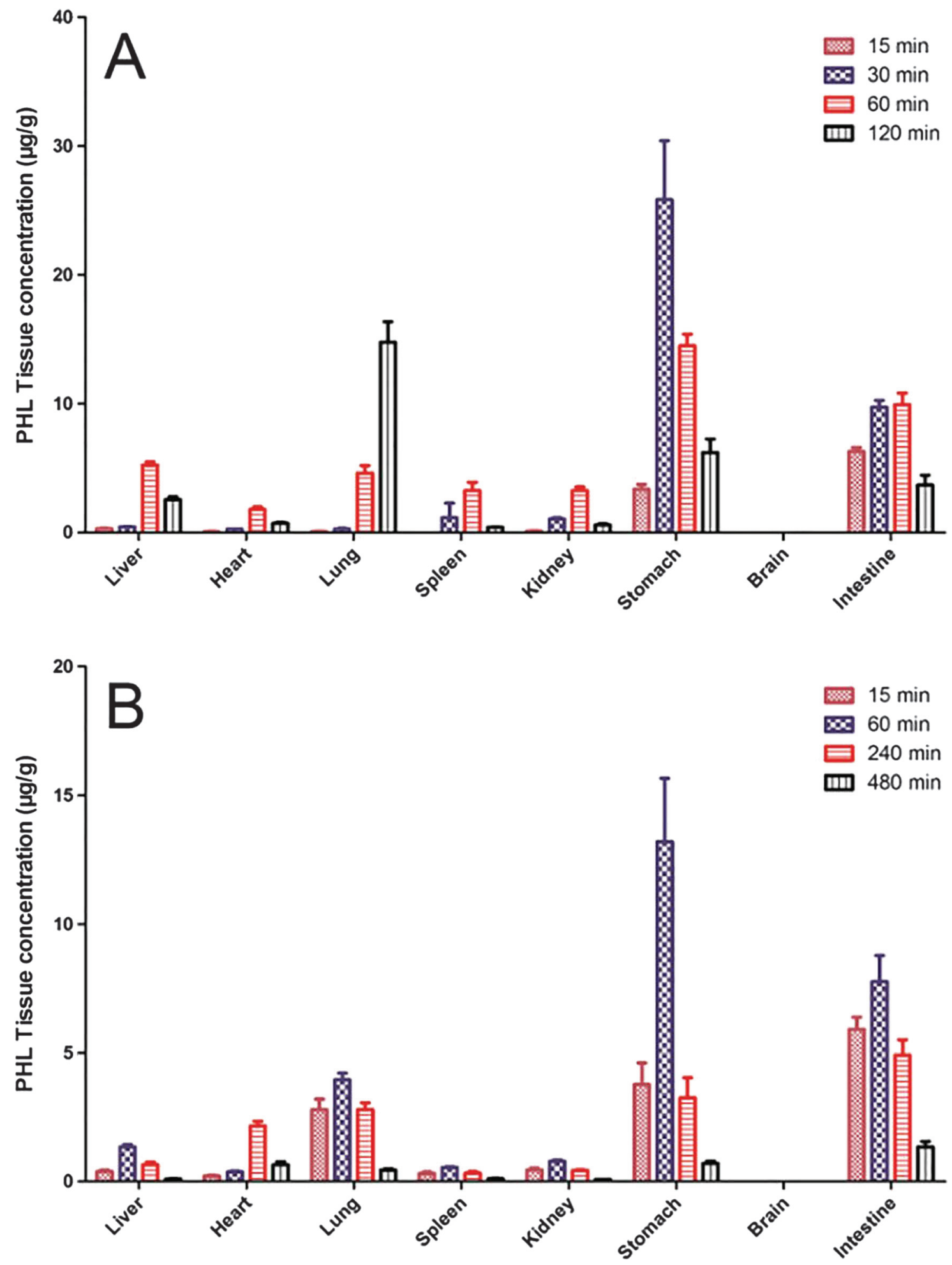

Figure 4. The concentration-time profile of PHL in tissues after oral administration of $100 \mathrm{mg} / \mathrm{kg}$ PHL (A) and $160 \mathrm{mg} / \mathrm{kg}$ TAPHL (B) to rats

obtained data showed that TAPHL could effectively increase the bioavailability and extend the duration of action of PHL. Tissue distribution studies demonstrated that PHL could be rapidly and widely distributed into tissues but could not effectively cross the BBB in rats. After oral administration of TAPHL to rats, its tissue distribution to rats was similar as that after oral administration of equimolar TAPHL. In addition, higher recoveries of PHL after administration of TAPHL indicated that TAPHL can reduce the excretion of PHL. The present in vivo pharmacokinetics, tissue distribution, and excretion studies of PHL and TAPHL in rats will provide helpful information for the development of suitable dosage forms and clinical references on rational administration.

\section{Conflict of Interest}

The authors declare no conflict interest.

Acknowledgments. This project was supported by the National Natural Science Foundation of China (grant nos. 81272175 and 81603313) and the Science and Technology 

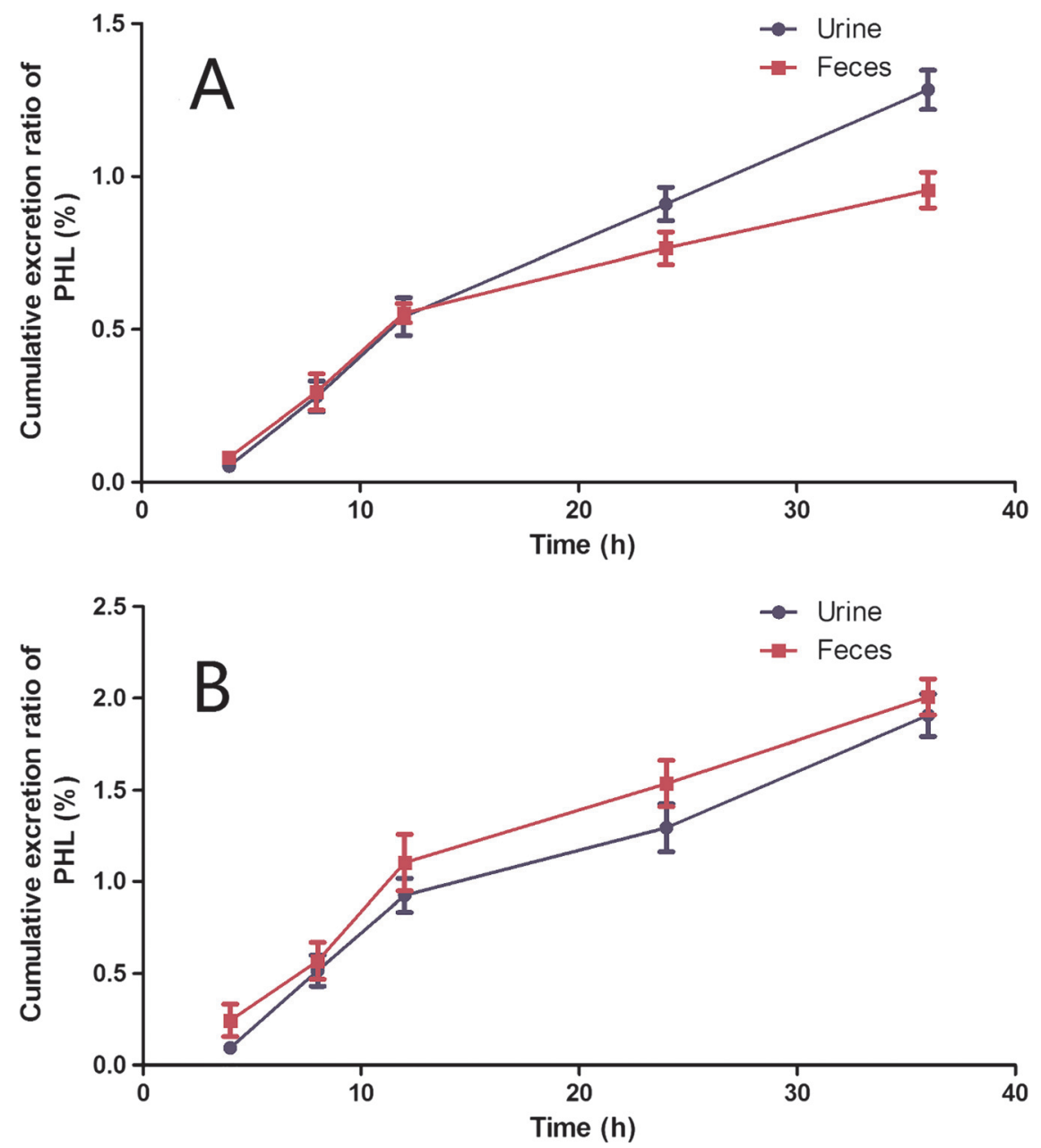

Figure 5. Urinary and fecal cumulative excretion of PHL in rats after oral administration of $100 \mathrm{mg} / \mathrm{kg}$ PHL (A) and $160 \mathrm{mg} / \mathrm{kg}$ TAPHL (B)

Innovation Project Plan of Shaanxi Province (grant no. 2014FWPT-11).

\section{References}

1. Heim, K. E.; Tagliaferro, A. R.; Bobilya, D. J. J. Nutr. Biochem. 2002, 13 , pp. 572.

2. Wang, X.; Poole, R. C.; Halestrap, A. P.; Levi, A. J. Biochem. J. 1993, 290, pp. 249-258.

3. Hertog, M. G.; Kromhout, D.; Aravanis, C.; Blackburn, H.; Buzina, R.; Fidanza, F.; Pekkarinen, M. Arch. Intern. Med. 1995, 155, pp. 381-386.

4. Guimarães, R.; Barros, L.; Carvalho, A. M.; Ferreira, I. C. F. R. Phytotherapy Res. 2011, 25, pp. 1209.

5. Stocker, P.; Yousfi, M.; Djerridane, O.; Perrier, J.; Amziani, R.; Boustani, S. E.; Moulin, A. Biochimie 2004, 86, pp. 919-925.

6. García-Lafuente, A.; Guillamón, E.; Villares, A.; Rostagno, M. A.; Martínez, J. A. Inflammation Res. 2009, 58, pp. 537-552.

7. Guardia, T.; Rotelli, A. E.; Juarez, A. O.; Pelzer, L. E. IL Farmaco 2001, 56, pp. 683-687.

8. Kim, H. P.; Son, K. H.; Chang, H. W.; Kang, S. S. J. Pharmacol. Sci. 2004, 96, pp. 229

9. Ferrándiz, M. L.; Alcaraz, M. J. Inflammation Res. 1991, 32, pp. 283-288.

10. Galati, E. M.; Monforte, M. T.; Kirjavainen, S.; Forestieri, A. M.; Trovato, A.; Tripodo, M. M. Farmaco 1994 40, pp. 709.

11. Telang, R. S.; Chatterjee, S.; Varshneya, C. Indian J. Pharmacol. 1999 31, pp. 363-366

12. Mgl, H.; Pch, H.; Katan, M. B. J. Agr. Food Chem. 1992, 40, pp. 2379-2383.

13. Hertog, M. G.; Hollman, P. C.; Katan, M. B.; Kromhout, D. J. Nutr Cancer 1993, 20, pp. 21-29.

14. Zi, X.; Grasso, A. W.; Kung, H. J.; Agarwal, R. Cancer Res. 1998, 58, pp. 1920-1929.

15. Vaya, J.; Tamir, S. Curr. Med. Chem. 2004, 11, pp. 1333.
16. Cemeli, E.; Schmid, T. E.; Anderson, D. Environ. Mol. Mutage 2004, 44 , pp. 420 .

17. Ohno, S.; Shinoda, S.; Toyoshima, S.; Nakazawa, H.; Makino, T.; Nakajin, S. J. Steroid Biochem. 2002, 80, pp. 355-363.

18. Picq, M.; Cheav, S. L.; Prigent, A. F. Life Sci. 1991, 49, pp. 1979-1988.

19. Uda, Y.; Price, K. R.; Williamson, G.; Rhodes, M. J. Cancer Lett. 1997, 120, pp. 213-216.

20. Rezk, B. M.; Haenen, G. R.; Wj, V. D. V.; Bast, A. Biochem. Bioph. Res. Co. 2002, 295, pp. 9-13.

21. Picinelli, A.; Dapena, E.; Mangas, J. J. J. Agr. Food Chem. 1995, 43 pp. 2273-2278.

22. Miksicek, R. J. J. Steroid Biochem. 1994, 49, pp. 153-160.

23. Jonge, P. C. D.; Wieringa, T.; Putten, J. P. M. V.; Michiel, H.; Krans, J. $B B A$ - Bioenergetics 1983, 722, pp. 219-225.

24. Oresajo, C.; Stephens, T.; Hino, P. D.; Law, R. M.; Yatskayer, M.; Foltis, P.; Pillai, S.; Pinnell, S. R. J. Cosmet. Dermatol. 2008, 7, pp. 290-297. 25. Turturro, F.; Friday, E.; Welbourne, T. BMC Cancer 2007, 7, pp. $96-96$.

26. Csaky, T. Z.; Fischer, E. Diabetes 1981, 30, pp. 568-574.

27. Wu, C.-H.; Ho, Y.-S.; Tsai, C. Y.; Wang, Y. J.; Tseng, H.; Wei, P. L.; Lee, C. H.; Liu, R. S.; Lin, S.-Y. Int. J. Cancer 2009, 124, pp. 2210-2219.

28. Yang, K. C.; Tsai, C. Y.; Wang, Y. J.; Wei, P. L.; Lee, C. H.; Chen, J. H.; Wu, C. H.; Ho, Y. S. Mol. Carcinogen 2009, 48, pp. 420- 431.

29. Sabzevari, O.; Galati, G.; Moridani, M. Y.; Siraki, A.; O'Brien, P. J. Chem.-Biol. Interact. 2004, 148, pp. 57.

30. Chang, W. T.; Huang, W. C.; Liou, C. J. Food Chem. 2012, 134 pp. 972-979.

31. Boersma, M. G.; Van, D. W. H.; Bogaards, J.; Boeren, S.; Vervoort, J.; Cnubben, N. H.; van Iersel, M. L.; van Bladeren, P. J.; Rietjens, I. M. Chem. Res. Toxicol. 2002, 15, pp. 662-670.

32. Manach, C.; Donovan, J. L. Free Radical Res. 2004, 38, pp. 771-785.

33. Liu, Y.; Hu, M. Drug Metab. Dispos. 2002, 30, pp. 370-377.

34. Chan, S. C.; Chen, S. L.; Li, Y.; Yang, D. Puerarin derivatives and their medical uses 2006. 